\title{
"Azoar": apontamentos sobre transcriação na canção popular
}

\author{
Leandro Ernesto Maia*
}

Sobre Dona Conceição dos mil sambas (the one-thousand sambas woman) Conceição Rosa Teixeira é conhecida na cidade de Pelotas pela sua maternidade comunitária e atuação social, tendo criado mais de cem filhos deixados à porta da sua casa na Vila Castilho, em Pelotas, Rio Grande do Sul. Sua atuação como compositora, no entanto, é praticamente desconhecida na cidade. Ao compor mais de mil sambas sem receber educação musical formal, Dona Conceição Teixeira oferece a oportunidade de abordar o processo criativo de canções em aspectos tais como aprendizagem informal (GREEN, 2002), intuição (SWANWICK, 1994) e conhecimento tácito (POLANYI, 1967). Considerando a interdisciplinaridade inerente ao gênero de canção popular, a pesquisa sobre as obras de Dona Conceição Teixeira combina etnografia e análise musical para entender como o habitus cancional se manifesta em seus sambas por meio da identificação de disposições musicais (MAIA, 2019). O presente artigo enfatiza os aspectos concernentes à tradução, versificação, ou transcriação, da canção popular como elementos subsidiários ao estudo de processos criativos no contexto da pesquisa realizada.

\footnotetext{
${ }^{*}$ Universidade Federal de Pelotas (UFPel).
} 
Aspectos do campo da tradução revelaram-se cruciais no contexto de realização da pesquisa no exterior, uma vez que foi necessário refletir e interpretar musicalmente as canções de Dona Conceição para pesquisadores em eventos acadêmicos no estrangeiro. A metodologia desenvolvida, intitulada "Esquema de Pesquisa Multidimensional" (MAIA, 2019, p. 52) envolve observação, entrevista, transcrição, filmagem, gravação, análise musical e colaboração artística, incluindo a interpretação musical como forma privilegiada de análise musical. Compatibilizando abordagem etnográfica reflexiva com a crítica genética, conforme proposta por Chaves (2012) e Salles (2008), o trabalho busca avançar no campo da pesquisa em música popular, revelando também aspectos não verbalizados do fazer dos cancionistas populares em seu habitus cancional (MAIA, 2019)

\section{Contextos Cancionais}

Na tarde do dia 6 de novembro de 2011, Dona Conceição Rosa Teixeira finalizou a canção "Atitude", com título alterado posteriormente para "Azoar", escrita no verso de uma caixa de maisena (Figura 1). Ainda que um suporte inusitado para a criação musical, o meio utilizado por Conceição oferece informações valiosas sobre processos criativos. Realizada de forma casual, diferentes momentos da criação de Dona Conceição coincidem com uso de canetas azul e preta, explicitando que trechos da canção foram compostos em momentos distintos. Coincidentemente, os trechos em azul e preto correspondem às partes ' $\mathrm{A}$ ' e ' $\mathrm{B}$ ', seguindo o padrão estrutural da composição do samba em duas partes, sem que a intenção da compositora fosse a de ilustrar as partes, tendo a troca de canetas ocorrida por força das circunstâncias. Sem a intenção de demonstrar as partes estruturais do samba, a compositora possivelmente interrompeu seu fluxo criativo frente a algum 
evento que resultou no extravio da caneta. Desta forma, percebe-se que as partes do samba são concebidas em bloco, de forma integral. O manuscrito de "Azoar" ilustra de maneira cristalina a forma como realização intuitiva da compositora segue tradições e dispositivos lírico-musicais pré-existentes. É possível perceber também que, mesmo criando no "calor da hora", Conceição reelabora sua composição através de reescritas, rabiscos e substituição de palavras. Isto é perceptível, por exemplo, no título da canção, reescrito em tinta preta.

No estudo dos processos criativos em canção popular, que conciliam crítica genética, etnografia e análise musical, faz parte do trabalho de um(a) cancionista-pesquisador(a) interpretar a canção estudada, tomando-a para si de maneira a identificar esforços, corporeidades e situações perceptíveis apenas durante fazer artístico. No caso de "Azoar", apresentada originalmente apenas com voz e batucada de mão, outros procedimentos como transcrição musical via notação e harmonização ao violão foram essenciais. Desta forma, torna-se possível compreender intencionalidades não verbalizadas pelos criadores, algo característico do fazer de cancionistas populares, cujos processos são impregnados de "conhecimento tácito". O termo, designado por Michael Polanyi, evidencia que "nós sabemos mais do que somos capazes de comunicar" e que "grande parte deste tipo de conhecimento não pode ser descrita através de palavras" (POLANYI, 1967, p. 4). Trata-se de um conhecimento prático, que obedece a outros processos, que não necessariamente verbais, ou mesmo conscientes. Além do aspecto não-verbal do conhecimento cancionista, a performance parece cumprir um papel decisivo nos processos criativos.

“Azoar" é criada, portanto, como um samba tradicional em duas partes. Um breve levantamento do trabalho de Noel Rosa, considerado um 
dos principais consolidadores do gênero samba no Brasil (CHEDIAK, 1991), é suficiente para confirmar a predominância da forma $A B$ neste gênero de canção popular. Nos sambas também é comum ter um processo colaborativo de duas partes: o primeiro compositor escreve uma parte A completa com melodia e letra, e um parceiro escreve uma parte B completa. Segundo Cláudia Neiva de Matos:

Um dos parceiros escreveu a primeira parte da música e o outro parceiro a segunda. Este procedimento é derivado do modus operandi da música préfonográfica tradicional, baseada na sequência de refrão coral e estrofes solo improvisadas. (MATOS, 2011, p. 7)

No samba, e este é o caso de Dona Conceição, a estrutura em duas partes $(\mathrm{AB})$ pode ser encontrada com frequência, diferentemente do choro, tradicionalmente apresentado em três partes alternadas em forma rondó (ABACA). Como vimos, o manuscrito de Dona Conceição mostra que as partes A e B foram compostas em momentos diferentes, revelando um habitus estrutural onde a melodia e a letra emergem em um bloco de palavras e música surgindo ao mesmo tempo. 

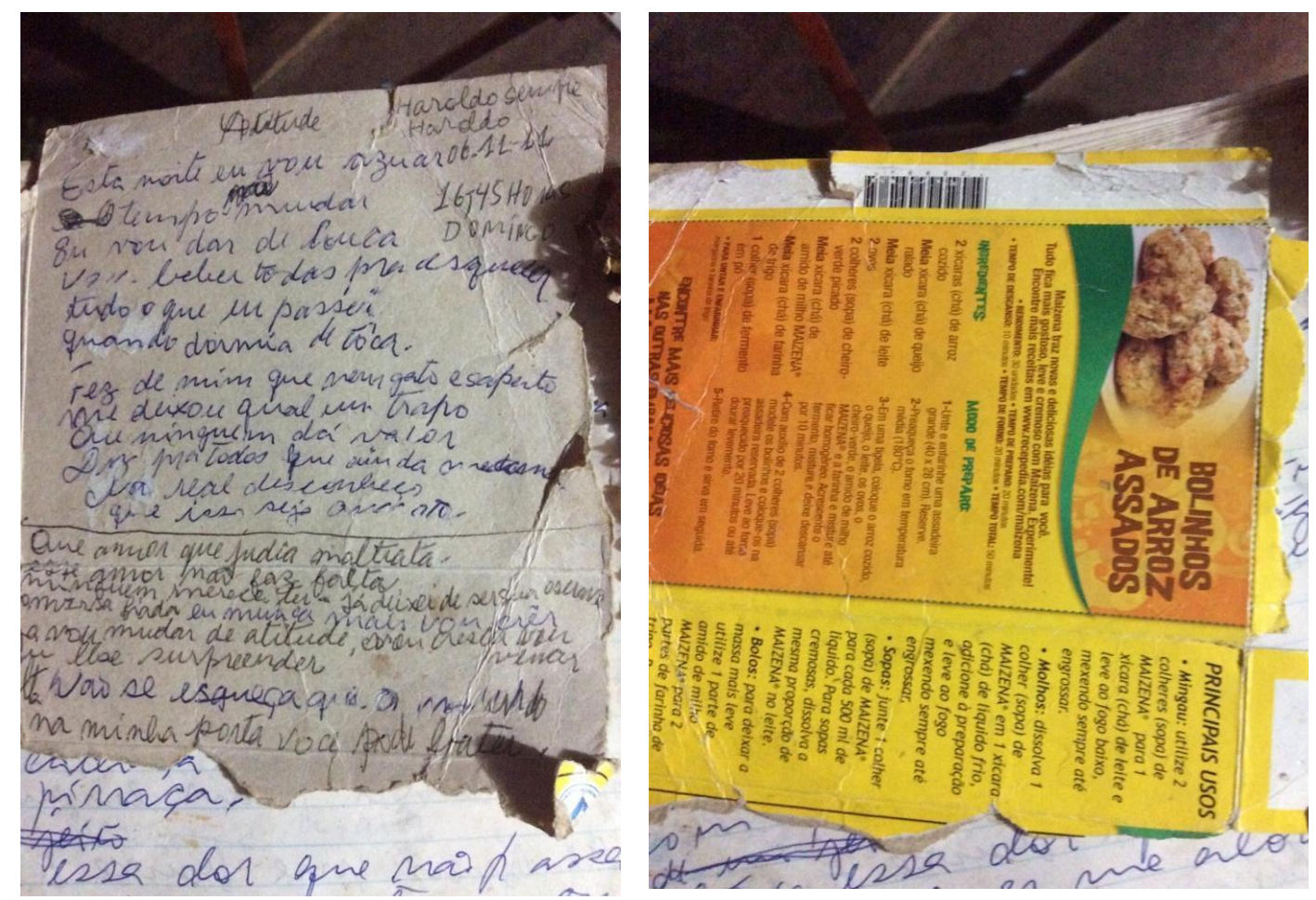

Figura 1 - Manuscrito de "Azoar" no verso de uma embalagem.

Considerando-se o foco do presente texto nos aspectos ligados à tradução/transcriação, não é possível detalhar o argumento de que o saber da cancionista consiste de um conhecimento tácito articulado pelo habitus. Cabe, no entanto, ressaltar o caráter prático deste saber como advindo de "um sistema não-individual de estruturas internalizadas" (BOURDIEU, 1977, p. 86). Assim como uma linguagem, o saber cancionista apresenta elementos de "sua própria sintaxe, num sentido amplo. A codificação tonal de alturas, métrica, ritmo e agrupamentos, são mecanismos fundamentais de organização hierárquica em música" (ASANO; BOECKX, 2015, p. 2).

No contexto de uma pesquisa realizada no exterior, foi imperativo buscar uma versão de Azoar "para inglês ver", no sentido de possibilitar sua comunicabilidade e entendimento em língua estrangeira. Para tanto, foi 
necessário sistematizar procedimentos com ênfase na sonoridade dos esquemas criativos, preservando identidades musicais em novos contextos enunciativos. Sendo assim, a transcriação serviu também para ilustrar os mecanismos criativos de Dona Conceição, servindo como método complementar de análise cancional, ao revelar aspectos não perceptíveis de imediato na língua nativa.

Transcriação é o termo cunhado pelo teórico, poeta e tradutor Haroldo de Campos (1929 - 2003), referente à tradução de poesia (CAMPOS, 1969). Em relação aos aspectos transculturais, a transcriação foi utilizada como recurso em momentos específicos da pesquisa sobre processos criativos para contextualizar tomadas de decisões, além de servir como uma ferramenta de análise e distanciamento do pesquisador do objeto de estudo. Ocorre que tampouco poesia e música podem ser traduzidas literalmente, necessitando adaptação e recriação com o objetivo de preservar intenções poéticas originais e as relações entre palavras e efeitos poéticos, evitando a separação entre conteúdo e forma. A transcriação também se refere a uma tradução intercultural e intersemiótica, onde a cultura receptora irá interpenetrar e transformar a original.

A tradução não é um fluxo unidirecional. Nesse sentido, é um processo de tradução amparada por procedimentos analíticos em que palavras, significados poéticos, formas e efeitos estéticos conciliam "criação e crítica" (CAMPOS, 2006, p. 31-48). Concebida como um processo "antropofágico" através de uma teoria de assimilação cultural, a transcriação possibilita que a cultura ocidental seja reapropriada por culturas locais, de matrizes nativas e africanas.

\section{A transcriação como ferramenta para o estudo de canção popular}


Para possibilitar que "Azoar" seja cantada em inglês, a transcriação revelase também fundamental como ferramenta de compatibilização entre análise e performance cancional, subsidiando o processo de tradução interpretativa da canção. Nesse processo, é importante manter a relação entre palavras, música e efeitos poéticos, evitando a separação entre conteúdo e forma. Ressaltando os aspectos transculturais, cabe salientar que a cultura receptora interpenetra e transforma a original, num processo de canibalização cultural impregnado na vida brasileira, conforme o Manifesto Antropófago, de Oswald de Andrade (1928). Para John Milton (1998, p. 134): “O canibalismo pode ser visto como uma metáfora que expressa a situação do escritor póscolonial brasileiro". A literatura e o escritor da metrópole passam a ser não somente aceitos, uma vez que é impossível ignorar essas influências dominantes, mas sim digeridos e reapropriados, num processo reverso. Haroldo de Campos afirma:

\footnotetext{
Na tradução de um poema, o essencial não é a reconstituição da mensagem, mas a reconstituição do sistema de signos em que está incorporada esta mensagem, a reconstituição da informação estética, não da informação meramente semântica. (CAMPOS, 1969, p. 100, grifo do autor)
}

Cabe ressaltar que, ao invés de um esforço de assimilação, o processo de transcriação de "Azoar" propõe um processo antropofágico ao revés, pois a canção brasileira passa a ser servida à mesa da cultura estrangeira, mesclando temperos nativos e ingredientes adaptados. Neste sentido, a versão transcriada de "Azoar" foi apresentada pelo pesquisador em voz e violão com o objetivo de ilustrar as ideias musicais de Dona Conceição Teixeira de forma mais direta, frente ao tempo limitado para apresentação de resultados de pesquisa em eventos acadêmicos no exterior. Isso também serviu como experimento, no sentido de observar a reação da audiência estrangeira e sua receptividade à obra da compositora pelotense. 
É importante ressaltar que a tradução de "Azoar" teve seu processo transcriativo realizado a quatro mãos, contando com a colaboração do musicólogo, pesquisador e cancionista britânico Joe Bennett. A atuação de Bennet contribuiu para converter as abundantes expressões idiomáticas em língua portuguesa para recursos imagéticos da língua inglesa. A partir do diálogo criativo com o colaborador britânico, foi possível sistematizar a experiência em uma tabela de transcriação, incluindo comentários e princípios para processos de transcriação colaborativa. Chama-se a atenção que este processo em parceria assemelha-se ao processo colaborativo em música popular, também concebido como um método de pesquisa artística, uma vez que:

\footnotetext{
As parcerias musicais fornecem evidências através do seu próprio processo: por necessidade, as ideias criativas devem ser comunicadas ao parceiro, tornando-se assim manifestas no mundo físico de alguma forma musical ou verbal, tornando-se, portanto, observáveis. (BENNETT, 2013, p.1)
}

Ao estabelecer uma notação musical que servisse às diferentes versões de "Azoar" (Figura 2), notas musicais em formato de losango foram utilizadas para indicar trechos em que há diferença melódica entre as versões em inglês ou português. Vale notar que as notas-losango afetam com mais frequência a versão inglesa, que geralmente possui palavras com menos sílabas que o português. Além disso, observa-se que mudanças de linguagem produzem alterações inevitáveis na música original, apesar do esforço para preservar sua integridade sonora.

Uma canção popular, via de regra, é um evento sonoro de palavras e alturas vocais que prescinde da notação musical (partitura). Como grande parte da música popular produzida sem a necessidade de uma escrita musical prévia, a partitura de uma canção serve apenas para ilustrar e 
descrever processos, contribuindo para converter eventos sonoros (gravações) em plataformas visuais (partituras). O objetivo primordial de uma transcrição é o de possibilitar a análise e o compartilhamento de ideias no espaço físico do texto impresso. Em outras palavras, a partitura musical de música popular resulta do fenômeno sonoro, e não o contrário. Segundo Muriel Swijghuisen Reigersberg, trata-se aqui do processo de transcrição musical descritiva:

\begin{abstract}
O objetivo da notação musical ou de um texto musical transcrito é que se possa registrar, no papel, o que ocorreu no som. Este é um texto descritivo e frequentemente usado por um terceiro, ou alguém não familiarizado com a música, para ajudar a entender os processos musicais presentes. Isso pode ser feito para fins analíticos e/ou de preservação, a fim de informar estudiosos e artistas. É principalmente na variedade descritiva do texto musical onde grande parte da tradução ocorre. (REIGERSBERG, 2013, p. 169)
\end{abstract}

Considerando o registro sonoro como um 'texto musical', é importante notar que a adaptação de uma canção brasileira para o inglês pode revelar aspectos não observados à primeira vista em seu contexto original. Como elemento-chave para processos transcriativos, é necessário priorizar a compatibilização entre as letras em português e inglês de acordo com os seguintes princípios, sistematizados durante a pesquisa:

1) Respeitar as métricas originais que caracterizam o gênero musical (ex: samba), usando palavras do cotidiano e melodia compatível com discurso verbal coloquial.

2) Prestar especial atenção aos acentos rítmicos, observando as características do gênero musical. No caso de um samba, o acento no segundo tempo do compasso e a predominância da articulação contramétrica. Em outras palavras: onde existe 
uma sílaba tônica em português, é necessário ter uma sílaba tônica também em inglês.

3) Privilegiar uma compatibilidade geral do significado textual, apesar de quaisquer ajustes textuais relativos à articulação do ritmo.

4) Evitar o canto melismático excessivo e preservar uma relação sílaba-nota, característico da canção brasileira.

5) Observar o uso de diferentes alturas em uma canção, com o objetivo de respeitar as relações entre notas mais agudas, mais graves, duração, velocidade e letra originais.

6) Preservar, na medida do possível, as relações originais entre a harmonia da melodia e o texto, incluindo alterações, resoluções, suspensões, retardamentos, antecipações e prosódias.

Tabela 1 - Princípios para a transcriação de canções

O conjunto de princípios descritos na Tabela 1 visa equilibrar alterações inevitáveis resultantes dos procedimentos de tradução da música original. Nesse sentido, o estilo musical e os efeitos poéticos são preservados na medida do possível: métrica, melodia, tensões, articulações rítmicas e mensagem lírica são consideradas envolvendo uma teia de significados musicais e textuais emaranhados. Pelo menos duas formas diferentes de conversão podem ser reconhecidas neste trabalho: áudio (texto musical) em visual (transcrição em partitura), além da tradução do português para o inglês. A transcriação aqui realizada, portanto, se refere à interação entre aspectos linguísticos e intersemióticos, considerando as expressões metafóricas e idiomáticas inerentes às canções.

"Azoar" é uma palavra de origem africana no português do Brasil (GELEDÉS, 2017), um verbo derivado do substantivo "zoeira", também "azoeira", que significa bagunçar, fazer festa, ou mesmo "chutar o balde". A compositora Conceição Teixeira não conhece exatamente a origem da palavra, mas dispõe plenamente de seu uso em seu léxico afro-brasileiro, 
aplicando-a perfeitamente para incorporar a narrativa verídica contada por amiga em sua luta por consideração, independência, opondo-se ao sexismo e a opressão manifestados pelo marido. Toda a letra em português é caracterizada pelo uso de expressões idiomáticas, ou "frases feitas". Juntamente com os princípios da Tabela 1, a transcriação da canção é ilustrada na plataforma indicada na Tabela 2, com base na observação complementar de:

- Expressões idiomáticas

- Coloquialidade

- Métrica (compatibilidade da letra com a melodia e com a prosódia originais)

- Rimas (preservando o esquema original, na medida do possível)

Azoar (Letra Original)

$A$

1. Essa noite eu vou azoar

2. O tempo vai mudar*

3. E eu vou (vou) dar de louca*

4. Vou beber todas pra esquecer

5. Do tempo que eu passei

6. Quando dormia de touca*

7. Fez de mim que nem gato e sapato*

8. Me tratou qual um trapo

9. Que ninguém dá valor (diz)

10. Diz a todos que ainda me ama 
11. Na real desconheço
12. Que isso seja amor

$B$

13. Que amor que judia maltrata?

14. Esse amor não faz falta

15. Ninguém merece ter

16. Já cansei de ser sua escrava

17. E em sua conversa fiada*

18. Eu não vou mais crer (se liga)

19. Se liga

20. Vou mudar de atitude

21. Vou crescer vou vencer

22. E vou the surpreender

23. Não se esqueça

24. Que o mundo dá voltas*

25. E que na minha porta

26. Você precise bater

27. E eu não vou atender

*Expressões idiomáticas

Plataforma de Transcriação/Commented literal translation/Esboço/Outline

1. Tonight I am going to mess up. Considering the often using of idiomatic expressions, 'azoar' will be trasncreated to 'Paint the whole town red'.

1. The weather will change. This is an idiom that means 'the situation or the attitude will suddenly change. The idiom 'as mad as a wet hen' seems to express the same intension. Inner rhyme hen - red.

1. And I will make myself crazy.

1. I will drink everything to forget.

1. The time that I spent. Inner rhyme forget - spent 
1. When I used to dress the sleeping cap. This is an idiomatic expression that means 'let someone fulling me, to have stupid behaviour'. Transcreation: When I was a stupid lady. Rhyme crazy - lady.

1. (He) Made me such as cat and a shoe. Idiomatic expression that means 'to humiliate', 'to manipulate', 'to make blind', 'to deceive'. "He did everything to freak me out"

1. Has treated me like a rag (tatter). Transcreation: has treated me like a dot

1. That nobody gives value. Transcreation: without any good

1. (He) tells everybody that he still loves me. Transcreation: he insists that he still loves me

1. In fact, I don't know. Transcreation: In fact I can't

1. If it is love. Transcreation: Believe in this kind of love

1. That love that hurts and mistreats? Trascreation: what love that bullies and mistreats

1. This love is not needed. Transcr.: That nobody needs

1. And anybody deserves it. Transcr.: any love like this

1. I am tired of being your slave.

1. And in your small talk. Transcr.: And such big poker face

1. I won't believe anymore. Transcr.: I will never more miss

1. Turn on yourself. Expression that means to pay attention. Transcr.: Come on!, Believe.

1. I will change my attitude. Transcr.: I will change my whole life/ my mind

1. I will grow and win. Transcr.: I don't wanna be your wife (ryme)

1. And I will surprise you.

1. Don't forget

1. That the world goes around. Transcr.: that the world changes

1. And that in my door. Transcr.: And for my revenge

1. You need to knock. Transcr.: I won't see you anymore

And I won't answer you. Even you ask me for.

Transcreated Song

A

1. Tonight I will paint the whole town red

2. As mad as a wet hen

3. I'll drive myself crazy

4. I will drink all beer to forget

5. The time that I spent 
6. Being stupid and dizzy

7. We played a game of cat and mouse

8. But your claws were too sharp

9. You didn't care

10. You told me an old love story

11. But I couldn't see

12. A happy ending over there

B

13. You hurt and you lie and you cheat

14. Well nobody needs

15. Any love like this

16. You can't treat me like I'm your slave

17. (And the) mask on your face

18. That I'll never miss

19. Believe

20. I will change my whole life

21. I don't wanna be your wife

22. And I will surprise you

23. Don't forget

24. What goes around

25. One day comes around

26. So don't knock at my door

27. I'm not there any more

Tabela 2 - Plataforma de Transcriação

Ao traduzir o samba de Dona Conceição Teixeira, assim como em outra canção popular, é essencial considerar tanto os aspectos semânticos, quanto os relacionados ao processo composicional, tais como métricas, 
rimas, encaixe da letra na melodia e a articulação rítmica. Optou-se pela expressão inglesa to paint the town red, literalmente "pintar a cidades de vermelho", devido ao caráter emblemático e à ênfase no processo de transcriação, evidenciando a coloquialidade no processo de tradução/versificação já no título da canção. Ainda que a expressão inglesa caracterize uma enunciação mais antiga e menos usual, sua escolha é aplicável para uma cantora-compositora com mais de oitenta anos de idade. Ambas as expressões - "Azoar" e Painting the town red - não têm tradução literal, mas são equivalentes em sentimento e caráter vinculado à linguagem informal cotidiana. Assim, um verbo infinitivo 'Azoar' de origem africana no português brasileiro, é transcriado por meio de uma expressão idiomática, tendo em vista a abundante presença de expressões desse tipo na versão original. Destaca-se aqui a colaboração de Joe Bennett no processo transcriativo dos versos 7 a 12 (Tabela 2), através de uma estrofe ao mesmo tempo diferente e associada a imagens e afetos originais.

Sem entrar em maiores detalhes de análise musical neste artigo, apresenta-se uma partitura de "Azoar" com o resultado final da transcriação (Figura 2). Vide que a primeira parte do samba é cantada com a tônica em lá maior, enquanto a segunda parte possui a tonalidade ré maior, a subdominante, seguindo também os padrões do estilo samba em termos de harmonia e estruturação musical. Ambas as partes apresentam articulação em anacruse, também uma característica estilística comum. 


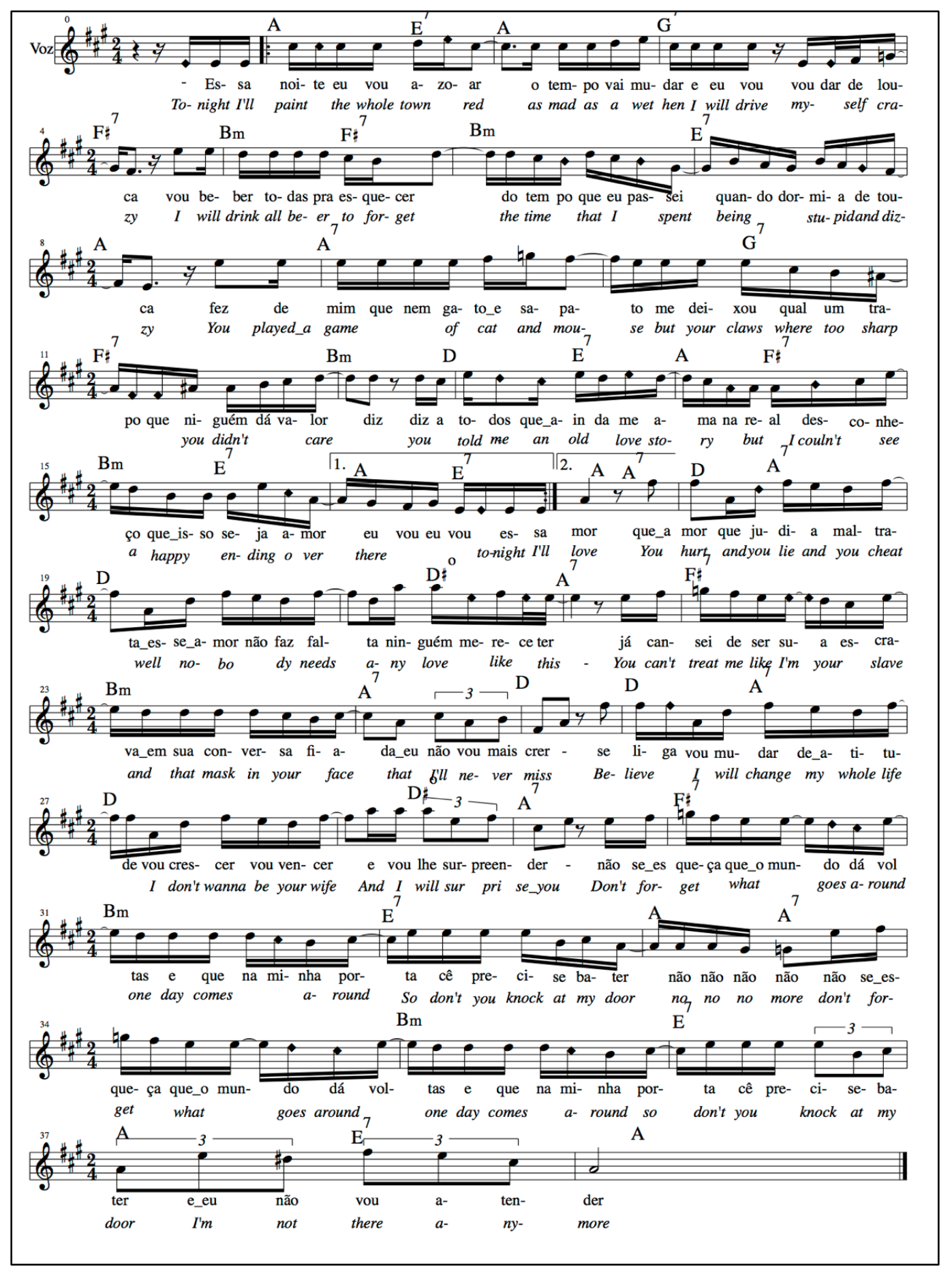

Figura 2 - Partitura de "Azoar", incluindo a transcriação para o inglês 
O processo aqui descrito não é uma ciência exata. Cada transcriação de canção resulta em uma obra diferente de acordo com a bagagem do tradutor-cantor e a finalidade da transcriação. Em relação ao processo de tradução/transcriação de canções (Tabela 1), é necessário dedicar especial atenção às relações entre música e letra reveladas através de análise cancional. A transcriação de "Azoar" possibilitou a compreensão da importância das relações existentes entre teorias analíticas, procedimentos de tradução e prática artística em música popular.

\section{Referências}

ASANO, Rie; BOECKX, Cedric. Syntax in language and music: what is the right level of comparison? Frontiers in psychology, v. 6, article 942, 2015.

BENNETT, Joe. Constraint, collaboration and creativity in popular songwriting teams. Farnham: Ashgate, 2013. p. 139-169 (The Act of Musical Composition: Studies in the Creative Process).

BOURDIEU, Pierre. The field of cultural production: essays on art and literature. Cambridge: Polity Press, 1993.

BOURDIEU, Pierre. Outline of a Theory of Practice. Vol. 16. Cambridge: Cambridge University Press, 1977.

CAMPOS, Haroldo de. A arte no horizonte do provável, e outros ensaios. São Paulo: Editora Perspectiva, 1969.

CAMPOS, Haroldo de. Metalinguagem e outras metas: ensaio de teoria e crítica literária. 4. ed. São Paulo: Perspectiva, 2006.

CHAVES, Celso Loureiro. Processo criativo e composição musical: proposta para uma crítica genética em música. In: Congresso Internacional da Associação de Pesquisadores em Crítica Genética, X Edição, Anais, p. 237-245. 2012.

CHEDIAK, Almir. Noel Rosa. Rio de Janeiro: Lumiar, 1991.

GREEN, Lucy. How popular musicians learn: a way ahead for music education. Aldershot: Ashgate, 2002.

MAIA, Leandro Ernesto. Poetics of song: songwriting habitus in the creative process of Brazilian music. Tese (Doutorado em Música) - College of Liberal Arts, Bath Spa University. Bath Spa, 2019. 
MATOS, Cláudia Neiva. Authorship and co-authorship (parceria) in samba: creative articulations and social boundaries. IASPM@ Journal. v. 1, n. 2, p. 1-14, 2011.

MILTON, John. Translation Theory in Brazil. Bulletin of Hispanic Studies. v. 75, n. 1, p. 123-136, 1998.

MINORS, H.J. (2013) Music, text and translation. London: Bloomsbury, 2013.

NEGRA, Geledés Instituto da Mulher. Conheça palavras africanas que formam nossa cultura. Disponível em: https://www.geledes.org.br/conheca-palavrasafricanas-que-formam-nossa-cultura/. Acesso em: 31 ago 2018.

POLANYI, Michael. The tacit dimension. London: Routledge \& Kegan Paul, 1967. REISGERSBERG, Muriel Swijghuisen. Transcription and Analysis as Translation: Perpectives from Ethnomusicology, in Minors, H.J. (2013) Music, text and translation. London: Bloomsbury Publishing Plc, 2013. p. 163-174.

SALLES, Cecília Almeida. Crítica genética. Fundamentos dos estudos genéticos sobre os processos de criação artística. São Paulo: Educ, 2008.

SWANWICK. Musical knowledge. Intuition, analysis and music education. London: Routledge, 1994.

\section{Resumo}

Ao estudar processos criativos da canção popular brasileira no exterior, pesquisadores deparam-se com o desafio de comunicar, via tradução, o conteúdo verbal e estético de obras lítero-musicais produzidas em contextos específicos de produção e significação no Brasil. Um desafio se impõe em particular ao cancionista-pesquisador, ao exercitar processos criativos em outros universos linguísticos, onde a tradução deve associar-se à performance musical na busca por reproduzir ao ouvinte estrangeiro o efeito semelhante ao produzido no ouvinte nativo. Este artigo discorre sobre a necessidade de refletir e sistematizar sobre as relações entre processos criativos, dispositivos cancionais e procedimentos de transcriação a partir do exemplo da canção "Azoar", da sambista pelotense Conceição Rosa Teixeira (1940-), que já compôs mais de mil sambas de maneira espontânea e intuitiva.

Palavras-chave: Tradução de canção; Processos criativos; Música popular. 


\begin{abstract}
When studying Brazilian songwriting creative processes in other countries, researchers face the challenge of communicating, via translation, verbal and aesthetic contents of literary and musical works produced in specific contexts of production and meaning in Brazil. An obstacle is imposed on the songwriter-researcher, when exercising creative processes in other linguistic universes, associated with musical performance aiming to engage the foreign listener to the similar effects produced in the native listener. This article discusses the need to reflect and systematize relationships between creative processes, songwriting dispositions and transcreation procedures based on the example of the song "Azoar", by the Brazilian songwriter Conceição Rosa Teixeira (1940-), who has already composed more than one thousand sambas in a spontaneous and intuitive way.
\end{abstract}

Keywords: Song translation; Creative processes; Popular music. 